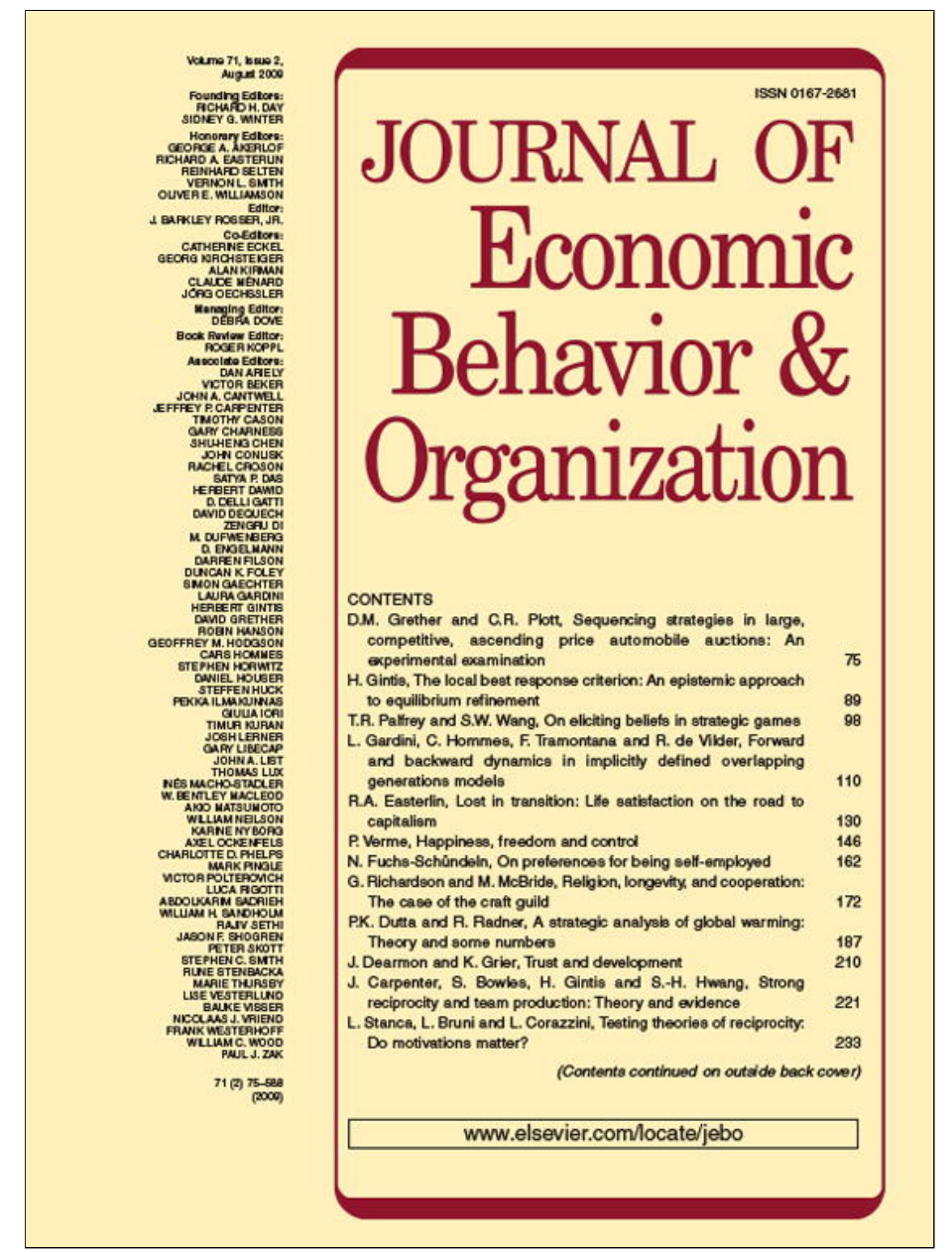

This article appeared in a journal published by Elsevier. The attached copy is furnished to the author for internal non-commercial research and education use, including for instruction at the authors institution and sharing with colleagues.

Other uses, including reproduction and distribution, or selling or licensing copies, or posting to personal, institutional or third party websites are prohibited.

In most cases authors are permitted to post their version of the article (e.g. in Word or Tex form) to their personal website or institutional repository. Authors requiring further information regarding Elsevier's archiving and manuscript policies are encouraged to visit:

http://www.elsevier.com/copyright 


\title{
Do consumers pay voluntarily? The case of online music ${ }^{\text {is }}$
}

\author{
Tobias Regner ${ }^{\mathrm{a}, *}$, Javier A. Barria ${ }^{\mathrm{b}}$ \\ a Max Planck Institute of Economics, Jena, Kahlaische Str. 10, D-07745 Jena, Germany \\ ${ }^{\mathrm{b}}$ Intelligent Systems $\mathcal{E}$ Networks Group, Department of Electrical and Electronic Engineering, Imperial College London, \\ Exhibition Road, SW7 2BT London, United Kingdom
}

\section{A R T I C L E I N F O}

\section{Article history:}

Received 24 April 2007

Received in revised form 31 March 2009

Accepted 1 April 2009

Available online 10 April 2009

\section{JEL classification:}

C24

C70

C93

D82

L82

\section{Keywords:}

Social preferences

Reciprocity

Music industry

Experience goods

Psychological game theory

Emotions

\begin{abstract}
A B S T R A C T
The paper analyses the payment behaviour of customers of the online music label Magnatune. Customers may pay what they want for albums, as long as the payment is within a given price range ( $\$ 5-\$ 18)$. Magnatune's comprehensive pre-purchase access facilitates music discovery and allows an informed buying decision setting it apart from conventional online music stores.

On average customers pay $\$ 8.20$, far more than the minimum of $\$ 5$ and even higher than the recommended price of $\$ 8$. We analyse the relationship between artists/labels and customers in online music. We consider social preferences, in particular concerns for reciprocity. The resulting sequential reciprocity equilibrium corresponds to the observed pattern of behaviour.

We conclude that Magnatune's open contracts design can encourage people to make voluntary payments and may be a viable business option.
\end{abstract}

(C) 2009 Elsevier B.V. All rights reserved.

\section{Introduction}

This paper covers and combines two areas of high recent interest: socially minded behaviour and the transforming digital media industry.

Social preferences of individuals have been increasingly studied in theoretical and empirical research. ${ }^{1}$ Our paper checks the external validity of the results from numerous laboratory experiments. While voluntary payments can be observed frequently in lab environments, we test these findings in a real-life context using data from an online music store.

The music business is of particular interest as this industry struggles to adjust its conventional business model to the challenges of online peer-to-peer (P2P) file sharing networks. Conventional online music stores attempt to implement Digital Rights Management (DRM) systems in order to stop illicit copying. However, effective copy protection appears to

is This work was partially supported by the EU-funded projects TIRAMISU (IST-2003-506983) and DANAE (IST-2004-507113). We would like to thank seminar audiences at the 5th ICT conference of the ZEW in Mannheim, EARIE 2005 in Porto, Royal Holloway and Tanaka Business School, Imperial College London. We are grateful to Maija Halonen-Akatwijuka, Osiris Parcero and anonymous referees for valuable comments. Finally, John Buckman has been essential for this paper as he provided the Magnatune data.

* Corresponding author.

E-mail addresses: regner@econ.mpg.de (T. Regner), j.barria@imperial.ac.uk (J.A. Barria).

1 See Camerer (2003) and Fehr and Schmidt (2003) for surveys of the literature in behavioural economics. 
be impossible to achieve as P2P file sharing still thrives. Moreover, the common DRM systems restrict customers in their consumption in various ways. ${ }^{2}$ The label and online store Magnatune (www.magnatune.com) goes another way. It lets customers choose from a given price range (\$5-\$18 for an album). Hence, customers can essentially pay what they want for music. Magnatune also allows comprehensive pre-purchase access to its songs so that potential customers can discover the music they really like.

The aim of the paper is to find out how much customers paid on average, what made them pay more than the bare minimum and whether the concept of such an open contract design can work in the market place. Therefore, we collected a data set of all the label's transactions over 18 months in order to analyse the payments that customers made.

The empirical analysis shows that the average payment per album is not only significantly higher than the minimum price (\$5), but it is also higher than the recommended price of $\$ 8$ suggested on the web site. We relate these findings to the theoretical background of information goods markets and take social preferences into account. The observed pattern of behaviour can be explained with concerns for reciprocity using the psychological game theory framework of Geanakoplos et al. (1989).

We study the principal-agent relationship between artists/labels and customers. The moral hazard aspect is inspired by the literature that started with Fehr et al. (1997). The benefits of contracts that give a mutual opportunity to reciprocate are described in a labour market setting where worker's effort is not contractible. We transform this approach to the context of information goods markets where payment becomes non-contractible due to widespread file sharing. Moreover, the importance of sampling opportunities for experience goods such as music is taken into account. Magnatune offers a free and comprehensive music discovery tool and this pre-purchase access to the album allows customers to make an informed buying decision. When customers have full pre-purchase access to songs they are interested in, they can experience the information good long enough to determine how much it is worth to them and decide whether they really want to buy it.

We focus on an intentions-based approach of social preferences that incorporates reciprocity into the utility function as pioneered by Rabin (1993). The resulting sequential reciprocity equilibrium following Dufwenberg and Kirchsteiger (2004) explains the voluntary payments found in the data. In addition to the frequent occurrence of voluntary payments in the data set our analysis also confirms that these payments are not randomly distributed. We observe type-dependent patterns among frequent customers, possibly caused by customer-specific underlying motivations for social preferences.

These results complement the experimental literature on social preferences by validating their findings outside of the lab. While the contribution behaviour of individuals has been studied in the field (see List and Lucking-Reiley (2002) or Frey and Meier (2004)), to the best of our knowledge this paper is the first field study of voluntary payments in a commercial online environment.

The following section describes the music label Magnatune in detail. Section 3 describes our data set, while Section 4 analyses it. Section 5 relates the findings to the theoretical background. The conclusions are in Section 6.

\section{The music label and online store Magnatune}

The label was founded in October 2003 and it has around 200 artists on contract. Magnatune prides itself of having a very strict selection process to guarantee high quality. The revenue is evenly split between artist and Magnatune. Music albums are sold via the label's online store where no DRM system is implemented. Files are not protected and quality and format is up to the customer. Even CD-quality files can be downloaded and the formats on offer give a good choice: WAV, MP3, OGG, FLAC and AAC. The payment is variable as customers can set the price themselves. The price range for an artist's album is $\$ 5-\$ 18$ and Magnatune recommends $\$ 8$. The actual price is selected by the customer in a pop-up menu where $\$ 8$ is the default setting.

Payment is processed by credit card or PayPal. It is not compulsory to leave an e-mail, customers can remain anonymous at Magnatune. Albums can be downloaded online or bought as a CD. A fee (\$4.97) for the physical costs of material and shipping is due for CD purchases. Magnatune is based in the USA, but as an online store it has customers around the world.

Magnatune's artists are categorised in various genres. There is a wide range of music available from classical music to Electronica, Jazz and Blues, Metal\&Punk, New Age, Rock and Pop, World and several more. Magnatune can be seen as a niche label that offers music of relatively unknown artists. Mainstream music of famous artists is not sold. Therefore, the focus of Magnatune - and the paper's - is music of less-known artists and subsequently uncertain quality.

This makes experience goods aspects even more important and they are well taken into account at Magnatune as music discovery is greatly facilitated. Full streaming access to all songs is provided in low or high quality. An online radio service lets customers try out songs conveniently. It can be used to listen to genre selections or artists' albums. Visitors of the site are allowed to test every song as often as they want. Essentially, consumers have all possible means available to sample music and find out how much an album is worth to them before having to make a decision about the payment. This stands in stark contrast to the usual practice of conventional online music stores where merely 30 s snippets of songs are available for sampling if at all. Magnatune's comprehensive pre-purchase access allows customers to make an informed buying decision.

\footnotetext{
2 The usage of P2P networks has not decreased despite numerous legal and technological activities of the music industry. Commonly, DRM restricts music discovery with no or very limited sample possibilities and restricts music listening with a limited number of permitted CD burns and transfers to mobile devices. Moreover, file formats may be incompatible with player software. Generally, established consumption patterns for music are not well taken into account.
} 
Table 1

Descriptive statistics.

\begin{tabular}{|c|c|c|c|c|c|c|}
\hline Variable & Obs. & Mean & Median & S.D. & Min & Max \\
\hline Payment (\$) & 14,367 & 8.197 & 8 & 2.301 & 5 & 24 \\
\hline Total customers & 7,620 & 1.86 & 1 & 2.657 & 1 & 49 \\
\hline Time difference (days) & 6,747 & 31.03 & 2 & 62.32 & 0 & 429 \\
\hline "female" dummy & 10,718 & 0.087 & 0 & 0.282 & 0 & 1 \\
\hline "no e-mail" dummy & 14,367 & 0.044 & 0 & 0.206 & 0 & 1 \\
\hline “CD” dummy & 14,367 & 0.039 & 0 & 0.195 & 0 & 1 \\
\hline "PayPal" dummy & 14,367 & 0.297 & 0 & 0.457 & 0 & 1 \\
\hline
\end{tabular}

Table 2

Country data.

\begin{tabular}{|c|c|c|c|c|c|c|c|}
\hline Country & Obs. & Mean & Median & S.D. & Min & Max & GDP/capita \\
\hline Canada & 371 & 8.08 & 8 & 1.82 & 5 & 18 & 29,866 \\
\hline Germany & 190 & 8.21 & 8 & 2.38 & 5 & 22.03 & 32,930 \\
\hline France & 163 & 8.52 & 8 & 2.09 & 5 & 18 & 33,015 \\
\hline Israel & 8 & 6.75 & 5 & 1.98 & 5 & 10 & 18,727 \\
\hline Italy & 65 & 8.67 & 8 & 3.85 & 5 & 22.03 & 28,782 \\
\hline Japan & 110 & 7.74 & 8 & 2.23 & 5 & 16 & 36,286 \\
\hline Mexico & 30 & 5.90 & 5 & 1.42 & 5 & 10 & 6,370 \\
\hline Singapore & 13 & 7.46 & 8 & 1.51 & 5 & 10 & 24,134 \\
\hline Spain & 55 & 7.67 & 8 & 1.49 & 5 & 12.24 & 24,577 \\
\hline Switzerland & 81 & 9.28 & 8 & 2.98 & 5 & 18 & 47,999 \\
\hline UK & 366 & 8.65 & 8 & 2.36 & 5 & 24 & 35,421 \\
\hline USA & 3838 & 8.18 & 8 & 2.14 & 5 & 18 & 39,453 \\
\hline
\end{tabular}

\section{Description of the data set}

Our data set goes back to the actual start of Magnatune's service in September 2003 and contains all 14,367 album purchases from then until January 2005. Apart from the payment we also collected the purchase date, an encrypted identifier of the customer, the gender and country of residence, the artist, the music genre, the means of payment, the type (download or $\mathrm{CD}$ ) and whether an e-mail address was left or not. In addition to these variables we computed the time difference between purchases, the total amount of purchases and the number of a respective purchase of a customer. Moreover, we created a dummy variable for female customers, if no e-mail was left, if a CD was purchased, if PayPal was used and also various country and genre dummies. ${ }^{3}$

The average payment for an album is $\$ 8.197$, the median and mode of the distribution are both $\$ 8$. The minimum payment made is the lower limit of the price range: $\$ 5$. Customers were allowed to pay in Euros and in British pounds, too. The same price range (5-18) was applied to these currencies, while our data set contains the (converted) dollar amounts. This is the reason why the maximum payment in the data set exceeds the actual upper limit of the price range. The different exchange rates have been taken into account in December 2004 as the price ranges for payments in Euros and pounds have been modified (in the meantime they are $4 €$ to $14 €$ with $6 €$ recommended and $£ 3$ to $£ 10$ with $£ 4$ recommended).

The data have been generated by 7620 different customers; most of them (4986) purchased only one album. On average customers bought 1.86 albums. The most albums a customer purchased are 49 . The time difference shows the time (expressed in days) between purchases. It is only generated with more than one purchase available. The following rows describe the dummy variables "female", "no e-mail", "CD" and "PayPal". 8.7 percent of the customers with gender data have been female. ${ }^{4}$ Only 4.4 percent of customers have chosen not to leave their e-mail. The purchase of proper CDs has been introduced in October 2004 which explains the low percentage of CDs bought (3.9 percent). They have been quite popular though despite the additional cost for shipping and packaging. PayPal has been used for 29.7 percent of purchases, while almost all of the other purchases have been handled via credit card (Table 1 ).

Table 2 shows the payment data for countries where Magnatune albums have been bought. ${ }^{5}$ The majority of purchases come from the USA (approximately 73 percent of sales). The list includes the main markets (USA, UK, Canada, EU), but also countries from other geographical areas given there is a reasonable amount of data available. GDP per capita numbers are added from the World Bank Statistics, 2004.

Finally, a number of different genres are offered at Magnatune. The music is grouped into the genres Classical, Electronica, Jazz and Blues, Metal\&Punk, New Age, Rock and Pop, World and Others. Classical music is the most popular genre with over 4000 purchases. World, Electronica, Rock and Pop and New Age follow with around 2000 purchases each.

\footnotetext{
3 Information about customers' gender and their country of residence could not be collected for the entire data set.

4 The association of a gender to the purchase was based on the name of the customer. This produced unambiguous results for approximately 75 percent of the observations. The remaining purchases could not be identified in terms of gender.

5 Country information has been collected in the period of 9-12/2004.
} 
Table 3

Payments over time.

\begin{tabular}{|c|c|c|c|c|c|}
\hline & \multicolumn{5}{|l|}{ Period } \\
\hline & 2003 Q4 & 2004 Q1 & 2004 Q2 & 2004 Q3 & 2004 Q4 \\
\hline Observations & 2283 & 3208 & 2703 & 2306 & 2648 \\
\hline S.D. & 2.21 & 2.20 & 2.18 & 2.17 & 2.21 \\
\hline
\end{tabular}

The variation in purchases has been fairly stable over time. Table 3 shows the payment data for the quarters that are available in full. There were 472 transactions before the 4th quarter of 2003 and 747 after the 4th quarter of 2004.

\section{Analysis of the data set}

\subsection{Regression}

The payment is the dependent variable in our regression and the equation we estimate is

$$
p=k+b \cdot X+\varepsilon
$$

where $k$ is the constant, $b$ is the vector of the coefficients, $X$ is the vector of our variables and $\varepsilon$ is the error term. The explanatory variables are the index of a purchase, the total purchases of the respective customer, the time difference and the dummies for female, no e-mail, PayPal, CD customers, for the countries and genres.

The given price range restricts the payment of customers. Therefore, the distribution of the payment is left-censored at $\$ 5$ and right-censored at $\$ 24$. A censored regression model appears appropriate for our data. The Tobit model takes limits of the range of the dependent variable into account, to ensure unbiased and consistent estimates. Table 4 lists the variables, their coefficients and respective standard errors for our Tobit maximum likelihood estimations. These are the results of the standard Tobit model, which assumes a single distribution function for the dependent variable. This approach seems plausible since the decision on whether to make a voluntary payment or not and the decision how much to pay in excess of the minimum (given one has chosen to make a voluntary payment) are not clearly separated ones. A two-equation model of Cragg (1971) would be an alternative to take the separate decisions into account (Amemiya, 1984).

We ran two regressions: one with the full data set of 14,367 observations using a random effects model controlling for artist heterogeneity, other with repeated purchases only (observations where the customer made a purchase before) using a random effects model controlling for customer heterogeneity. Repeated customers are recognised by their e-mail identifier. This is why the variable "No e-mail" is excluded from regression 2.

The index of a purchase is statistically significant at the 1 percent-level and it affects the payment negatively. It seems that initial payments are rather high, while later payments of frequent customers are lower. The total number of purchases of a customer is also significant as well as the squared term. This appears to hint at a quadratic relationship between the payment and the total purchases made.

In addition, the regression shows that customers who prefer to remain anonymous tend to pay less. When no e-mail is left, the payment is significantly lower. This fits into the psychological picture of free riders. The payment type (PayPal or credit card) did not have an impact on payments (when customer heterogeneity is considered). On the other hand, customers buying CDs paid significantly more. They might appreciate getting a CD with cover art more than the postage and package premium they have to pay when they order a $C D$. The dummy for female customers is not significant. Some of the genre dummies are significant among the 12 we have analysed. The genre 'Opera' had a negative impact on the payment. The genre 'Rock' had the most significant positive impact ( 5 percent-level). The country dummies show that payment is affected by where customers live. The effect of purchases from Switzerland and UK is significant and positive. The effect of purchases from Mexico and Israel is significant and negative. The time difference between purchases is positive and significant in the second regression. As the time difference for albums bought on the same day is zero, this may indicate that customers might apply an imaginary bulk discount, since they have the choice of how much to pay for albums.

The censored regression model is based on maximum likelihood and it assumes a normal distribution of the error term and homoscedasticity. A Bera-Jarque test confirmed the normality assumption. Our estimation results give some indication about what affects the voluntary payment for music. Naturally, the biggest explanatory factor for the payment is the actual value of the music to the respective customer which is not measurable. Understandably, the fit of the regression is not particularly good with 4 percent. However, our data analysis shows that Magnatune customers on average pay even more than what is actually recommended. Only 2081 of all 14,367 purchases (14.5 percent) were at the required minimum of $\$ 5$, the majority of purchases (7967 or 55.4 percent) were paid with the recommended $\$ 8$ and the average of all purchases is at $\$ 8.20$.

\subsection{Impact of country GDPs on payments}

We have seen that several country dummies were significant. However, the variation in the voluntary payments with respect to the country of residence has to be taken with caution. It can be explained by different underlying wealth lev- 
Table 4

Estimation results.

\begin{tabular}{|c|c|c|c|c|}
\hline \multirow[t]{2}{*}{ Explanatory variable } & \multicolumn{2}{|c|}{ Regression 1 (all observations) } & \multicolumn{2}{|c|}{ Regression 2 (repeated purchases) } \\
\hline & Coefficient & S.E. & Coefficient & S.E. \\
\hline Index of purchase & $-.0655^{* * *}$ & .0196 & .0151 & .0139 \\
\hline Index squared & .0006 & .0005 & -.0005 & .0003 \\
\hline Total purchases & $-.0338^{* *}$ & .0132 & -.0049 & .0127 \\
\hline Total squared & $.0017^{* * *}$ & .0003 & .0003 & .0003 \\
\hline Previous payment & - & - & $.0075^{* * *}$ & .0001 \\
\hline Time difference & - & - & $.0016^{* * *}$ & .0003 \\
\hline Genre Ambient & $-.2509^{*}$ & .1478 & $-.3410^{* * *}$ & .1207 \\
\hline Electronica & $.1913^{*}$ & .1176 & .0193 & .0949 \\
\hline Rock & $.2777^{* *}$ & .1219 & .1122 & .0964 \\
\hline New Age & .0896 & .1217 & .0391 & .0980 \\
\hline Classical & $.1615^{*}$ & .0988 & .0106 & .0832 \\
\hline World & .1151 & .1138 & -.0149 & .0930 \\
\hline Jazz & -.0781 & .1689 & .1752 & .1412 \\
\hline Relaxing & .1132 & .4025 & -.0192 & .2544 \\
\hline Blues & .2087 & .3618 & .3365 & .2707 \\
\hline Metal & -.0238 & .1711 & -.2335 & .1460 \\
\hline Opera & $-.8665^{* *}$ & .4906 & $-.8088^{* *}$ & .3832 \\
\hline Christian & .2847 & .3151 & .2153 & .2828 \\
\hline No e-mail & $-1.004^{* * *}$ & .1154 & - & - \\
\hline PayPal & $-.2070^{* * *}$ & .0525 & -.0102 & .0528 \\
\hline $\mathrm{CD}$ & $.9027^{* * *}$ & .1168 & .2069 & .1304 \\
\hline Female & .0860 & .0872 & -.1310 & .0903 \\
\hline UK & $.5554^{* * *}$ & .1460 & .1164 & .1502 \\
\hline Japan & $-.5696^{* *}$ & .2646 & $-.6469^{* *}$ & .2688 \\
\hline Germany & .1906 & .2007 & .0491 & .2011 \\
\hline Switzerland & $1.165^{* * *}$ & .3025 & .2534 & .3152 \\
\hline Canada & .0073 & .1436 & .0713 & .1438 \\
\hline France & $.4220^{* *}$ & .2185 & $.440^{* *}$ & .2540 \\
\hline Mexico & $-3.285^{* * *}$ & .5825 & $-2.785^{* * *}$ & .8589 \\
\hline Italy & .2302 & .3407 & .0463 & .3656 \\
\hline Spain & -.3377 & .3890 & .1271 & .3748 \\
\hline Singapore & -.2285 & .7432 & .2211 & 1.019 \\
\hline Israel & $-2.249^{* *}$ & .9716 & $-2.761^{* *}$ & 1.227 \\
\hline \multirow[t]{4}{*}{ Constant } & $8.168^{* * *}$ & .0984 & $1.653^{* * *}$ & .1362 \\
\hline & \multicolumn{2}{|c|}{ Number of observations: 14,367} & \multicolumn{2}{|c|}{ Number of observations: 6747} \\
\hline & \multicolumn{2}{|c|}{ Log likelihood = $-28,729.26$} & \multicolumn{2}{|c|}{ Log likelihood = -11,797.501 } \\
\hline & \multicolumn{2}{|c|}{2081 left-censored, 18 right-censored observations } & \multicolumn{2}{|c|}{1083 left-censored, 12 right-censored observations } \\
\hline
\end{tabular}

Random effects Tobit regressions, statistical significance $\left({ }^{*} 10\right.$ percent $/{ }^{* *} 5$ percent $/{ }^{* * *} 1$ percent $)$.

els. The different GDP per capita numbers seem to cause the variation and rather not cultural or regional differences. Fig. 1 plots the payment means and the GDP per capita of the analysed countries (see Table 2 for the respective numbers).

There appears to be a linear relationship between average voluntary payments in a country and its GDP per capita. The disposable income affects the willingness to pay which is only reasonable. Likewise, the CD price people are accustomed to in their local market (CDs cost less in, say, Mexico than in the USA) may influence their decision of how much to pay.

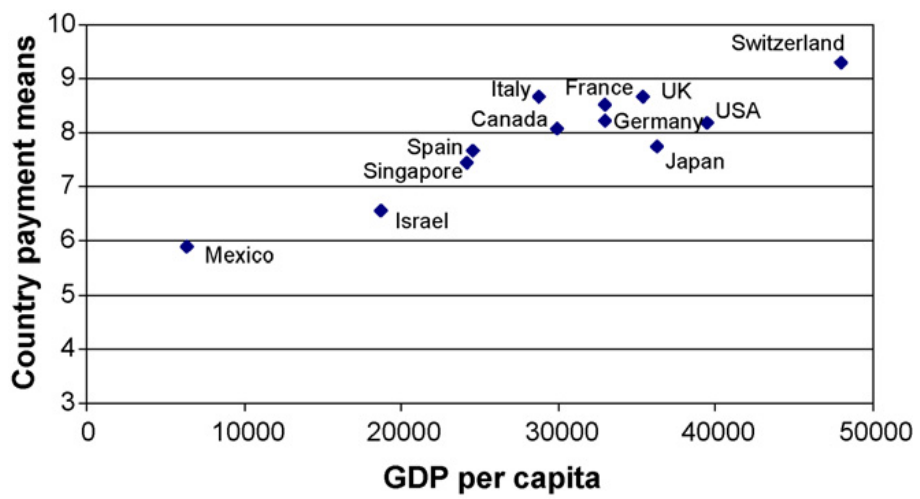

Fig. 1. Country payment means vs. GDP per capita. 
Table 5

Impact of price range conversion.

\begin{tabular}{|c|c|c|c|c|c|c|}
\hline & \multicolumn{2}{|l|}{ UK } & \multicolumn{2}{|c|}{ Germany } & \multicolumn{2}{|c|}{ France } \\
\hline & Obs. & Mean & Obs. & Mean & Obs. & Mean \\
\hline \multicolumn{7}{|l|}{$\begin{array}{l}\text { Payment } \\
\text { In \$ }\end{array}$} \\
\hline Before & 239 & 8.19 & 117 & 7.89 & 83 & 8.48 \\
\hline After & 77 & 8.13 & 38 & $7.34^{* *}$ & 34 & $7.76^{*}$ \\
\hline \multicolumn{7}{|c|}{ In local currency } \\
\hline Before & 28 & 12.68 & 19 & 11.27 & 20 & 10.28 \\
\hline After & 22 & $10.33^{* *}$ & 16 & $9.02^{* * *}$ & 20 & $8.20^{* * *}$ \\
\hline Total & 366 & 8.65 & 190 & 8.21 & 157 & 8.52 \\
\hline
\end{tabular}

Level of statistical significance $\left({ }^{*} 10\right.$ percent $/{ }^{* *} 5$ percent ${ }^{* * *} 1$ percent $)$ of the payments' mean after being different from the mean before in a Mann-Whitney test.

\subsection{Impact of framing effects due to the price range conversion}

Currency conversions are another potential cause for a bias in the countries' payment means. The fact that the price range was directly transformed into Euros and pounds might have led Europeans to spend more. While $\$ 8$ are recommended to customers paying in dollar, $£ 8 / 8 €$ were suggested to customers paying in pounds/Euro. The exchange rate during the observation period was approximately $1.75 \mathrm{USD} / \mathrm{GBP}$ and $1.25 \mathrm{USD} / \mathrm{EUR}$. Thus, a price range of approximately $\$ 8.75 \mathrm{minimum}$, $\$ 14$ recommended and $\$ 31.5$ maximum price was perceived by customers paying in pounds and $\$ 6.25 / \$ 10 / \$ 22.5$ by customers paying in Euro. Hence, framing effects might have occurred.

Price ranges were adjusted in $12 / 2004$ to accommodate for the exchange rates. $£ 3$ minimum, $£ 4$ recommended and $£ 10$ maximum $(4 € / 6 € / 14 €)$ have been used since then. In 2004 this translated into $\$ 5.25$, $\$ 7$ and $\$ 17.5$ for payments in pounds and $\$ 5, \$ 7.5$ and $\$ 17.5$ for payments in Euro-slightly less than the original dollar values $(\$ 5, \$ 8, \$ 18)$. Furthermore, making the payment in Euro or pounds was only an option. European customer could also simply pay in dollar and this option appeared more conveniently in the selection menu. Thus, we can group the European payment data by the period (before and after the conversion adjustment in 12/2004) and the currency used for the payment (dollars or pounds/Euro).

We focus on the three European countries with the most observations (UK, Germany and France) in order to analyse the effects induced by the suggested price range. Table 5 shows the data before and after the adjustment, separated by the countries and whether the payment was made in $\$$ or the local currency.

We ran Mann-Whitney tests to see whether there was a significant effect on the payment behaviour caused by the price range adjustment. We compared the payments before and after the correction took place in 12/2004. When customers paid in local currency, the payments dropped significantly for all countries. In contrast, only payments from German customers dropped as well at a significant level, when we consider the "control group" of payments made in \$. An increase in sales can be noticed when comparing the 2 months before the change $(10+11 / 2004)$ to the 2 months after (12/2004 and 1/2005): from 14 to 22 transactions in UK, from 12 to 16 transactions in Germany and from 19 to 20 transactions in France.

The suggestions of the web site appear to have a significant effect on the payment decision of customers. A reduction of minimum, recommended and maximum price leads to a significant decrease in average payments. It seems that the voluntary payments are very sensitive to such framing. The drop in average payments is however offset by the increase in volume.

\subsection{Payment patterns of frequent customers}

Another interesting aspect of the collected observations is how the voluntary payments are distributed. Do they occur in rather random fashion within the transactions of specific customers or do they mainly differ across customers?

We therefore clustered the observed transactions based on the previous payment made into the groups minimum, default, and high (>\$12) payment. With $\$ 5$ as previous payment, average payment was $\$ 5.49$, with a previous payment of $\$ 8$, the average payment was $\$ 8.01$ and with more than $\$ 12$ as previous payment, average payment was $\$ 12.29$. Moreover, the previous payment explained the current payment with high significance in the regression of repeated purchases.

In order to get an even better understanding about the tendency of customers to make a decision based upon a consistent underlying motivation or not, we analysed the payment patterns of 36 customers who had more than 15 transactions. Four different groups can be easily distinguished. These are customers who essentially paid the minimum of $\$ 5$, the default of $\$ 8$, customers who paid significantly more than the default (on average) and the ones who paid less over time (decreasing time trend). The diagrams of Fig. 1 show representative customers for each group. 20 customers paid the default of $\$ 8$ ( 9 always $\$ 8,11$ with minor deviations like id6252 in Fig. 2), 4 paid mostly the minimum (1 always $\$ 5$ ), 6 paid more than the 
id6252

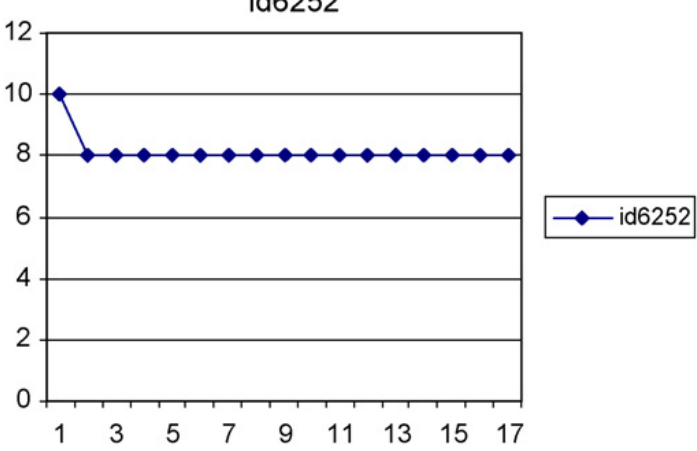

id960

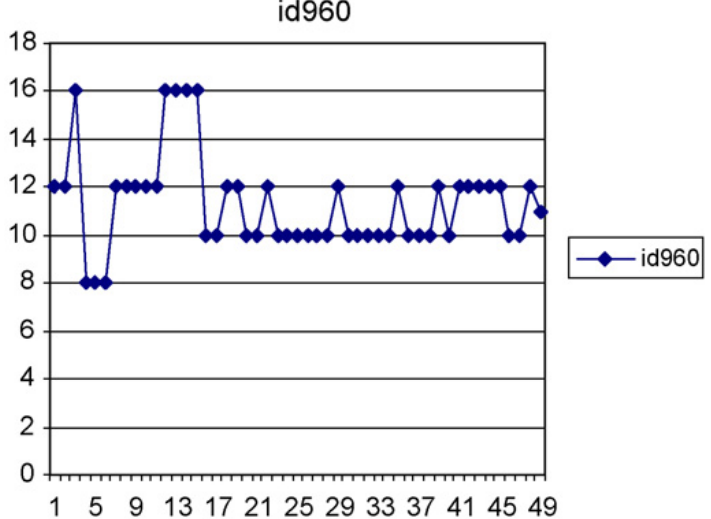

id211

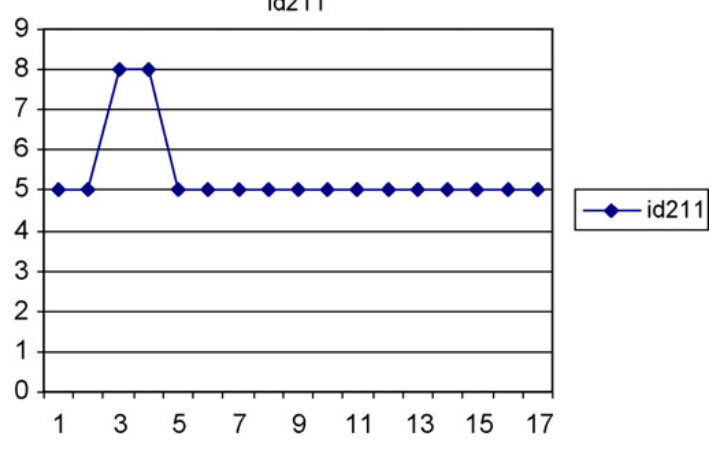

id4906

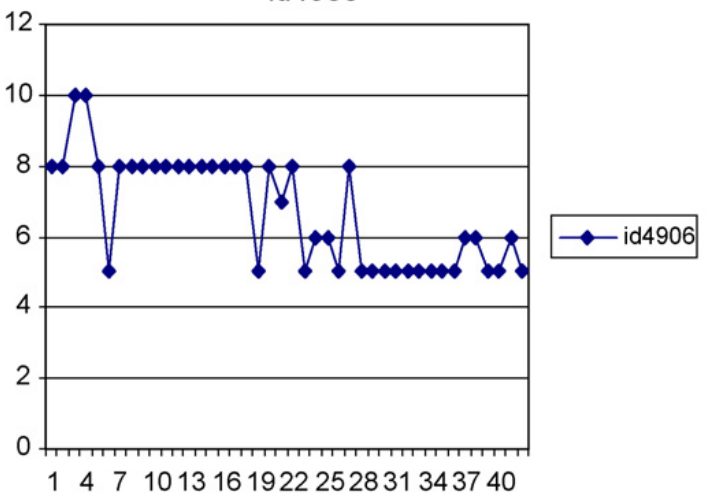

Fig. 2. Representative customers for each identified group.

default and 4 exhibited a decreasing pattern. ${ }^{6}$ It appears that customers' paying behaviour is indeed driven by underlying motivations that are specific to individuals.

\section{Theoretical background}

The online music industry mainly consists of labels, intermediary online stores and artists on one side and customers on the other. Artists create music, which is purchased by customers via the label's (or an intermediary's) web site. ${ }^{7}$ In the sector of relatively unknown artists Magnatune can be seen as an alternative to the conventional music business model. In this specific market labels have the choice between the conventional approach (limited access beforehand and a fixed price) and the Magnatune concept.

Two aspects of information goods markets play an important role in this context. Potential consumers of information goods (like online music) are increasingly difficult to exclude from consumption due to the widespread availability of files in P2P networks. Information goods are also experience goods and their actual value might be unclear to customers prior to the purchase. We consider these aspects in order to analyse the strategic decisions labels/artists face in this market. Our analysis takes social preferences into account ${ }^{8}$ and relates to the empirical results.

\subsection{Information goods markets}

Payment moral hazard describes the uncertainty of principals with respect to the payment of agents in information goods markets. The relationship between principal (label or artist) and agent (customers) is about the agent making a payment in exchange for the consumption of music. While this contractual relationship is very trivial to enforce for physical goods

\footnotetext{
${ }^{6}$ The transaction prices of only two frequent customers did not fit any of the four categories. The payment patterns of all 36 analysed customers are available upon request.

7 The interests and characteristics of artists and their labels are usually not too aligned in the music industry and artists and labels should therefore not be treated as one entity. However, Magnatune is certainly an exception to that. Its slogan is: "We're a record label. But we're not evil." (www.magnatune.com). It shares revenues equally with the artists. A direct connection between the payment of the customer and the income of the artist can be seen. We therefore do not distinguish between artists and the label.

8 Besides social preferences, reputation concerns are another possible theoretical explanation for generous payments in repeated interaction. However, music customers generally know that they do not enter a specific relationship with the artist when they decide to purchase an album. The artist might appreciate the voluntary payment of a customer and the customer might even be identifiable by the email address, but still the next album will be produced for the general audience and not for a specific customer. This is important, because it excludes strategic considerations like reputation as the motivation for voluntary payments.
} 
(CDs) of the traditional music industry, it is far from that for "weightless" music (downloads). P2P networks make files nonexcludable, e.g. they could be consumed without paying for them. The principal - artists and labels - does not know whether consumed goods have been paid for by agents or at least they cannot enforce payment. This information asymmetry causes non-contractibility of the payment. Fehr et al. (1997) point out the benefits of mutual opportunities to reciprocate in moral hazard environments, when they analyse a simple labour market with firms, workers and excess supply of workers. ${ }^{9}$ Our approach is similar, albeit adjusted to the described payment moral hazard in information goods markets.

Information goods are experience goods since customers do not know what they are worth to them until they experience them often enough. Hence, their exact value to the customer is quite unknown ex ante and the valuation rather develops until the good has been experienced often enough and the true worth has been established. While there is always uncertainty regarding the ex post utility of an information good in a conventional sale, ${ }^{10}$ as described Magnatune customers are much better aware of the ex post utility of music they buy. Without such a chance to experience the information good, customers risk ending up with a disappointing purchase. Buyer's remorse can result and this uncertainty reduces the willingness to pay of customers who consider a purchase based only on the sample or description of the music. This disappointment can be avoided, when customers have full pre-purchase access to songs they are interested in. They can experience the information good long enough to determine how much it is worth to them and decide whether they really want to buy it.

\subsection{Online music}

In the standard approach of contract theory the principal implements second-best contracts based on incentive compatibility and a participation constraint. ${ }^{11}$ The set up of Magnatune represents an alternative contract design. The offered contract is rather incomplete due to the variable pricing scheme and the agent has the opportunity to respond to the action of the principal.

The strategic interaction between label/artists (M) and customers (C) is sequential. First, M decides whether to allow free comprehensive pre-purchase access to the music or not. Then, the customers make their purchase and payment decision. Their value from consumption is $v$ and $M$ receives the payment $p$.

We distinguish between two levels of pre-purchase access to music. Very limited possibilities to sample songs as it is common in conventional online music stores restricts the music discovery of customers. Instead, comprehensive prepurchase access (as provided by Magnatune) allows sufficient sampling and customers are well-informed about music before they have to make a purchase decision. According to recent survey results (Indicare, 2005) streaming access to songs is not a substitute for buying them as customers prefer to own music. Moreover, songs are real experience goods. Artists are not famous enough and they have not built up a reputation so that customers know their music already, which would make the sampling less important.

The value of an album's consumption depends therefore on the extent of pre-purchase access. When customers have full access and can sample songs on offer easily, they are able to pick the albums they really enjoy. They know their value from consumption is the full ex post value of music $v$. Limited access leaves them with uncertainty about the ex post value. They might not find the albums they will actually enjoy most or they possibly choose music that turns out to be disappointing. Knowing this, their purchase decision is based on the expected value $\varepsilon v$ which is less than the full ex post value $v$.

The payment for an album depends on the chosen access (limited or full) and whether the customer decides to be kind or nasty. Given full pre-purchase access the nasty choice of the customer would be to just pay the minimum price $p_{\text {min }}$ required for the purchase, while the kind choice is a voluntary payment of $p_{v o l}$ which is necessarily below the actual value $v$ of the album. When pre-purchase access is limited, the kind choice of customers would be to simply pay the default price of the store, which is $\bar{p}$. The nasty choice of customers is to try obtaining the file on P2P networks for free. A fraction of customers ( $\gamma$ of the whole population) will succeed in this and they do not pay for consumption. Only the remaining fraction $1-\gamma$ pay the store and the price that applies to customers making the nasty choice is the price under DRM taking leakage to the P2P networks into account:

$$
p_{D R M}=(1-\gamma) \cdot \bar{p} .
$$

The fraction of file sharers $\gamma$ is defined to be $0<\gamma<1$. Their access to P2P networks gives them less efficient sampling possibilities than at $\mathrm{M}$ and their valuation is also the expected value $\varepsilon v$.

\subsection{The "Magnatune" game}

The structure of the game is illustrated in Fig. 3. The following numerical example illustrates the payoffs of the game. It builds on the actual prices of Magnatune. The minimum price to be paid under full access is $\$ 5$, the fixed price in online

\footnotetext{
${ }^{9}$ Three different contracts are simulated in experiments. While contract terms were exogenously enforced in the first treatment, workers were able to reciprocate in the second and both firms and workers were able to reciprocate in the third treatment. Effort levels of workers were significantly higher in the last treatment and a contract that gives the opportunity for mutual reciprocity was found to improve efficiency.

10 It can be reduced by short samples or recommendations, for instance, but never completely avoided.

11 In the information goods context of the music industry this could be a high fixed price enforced by strong copy protection and law.
} 


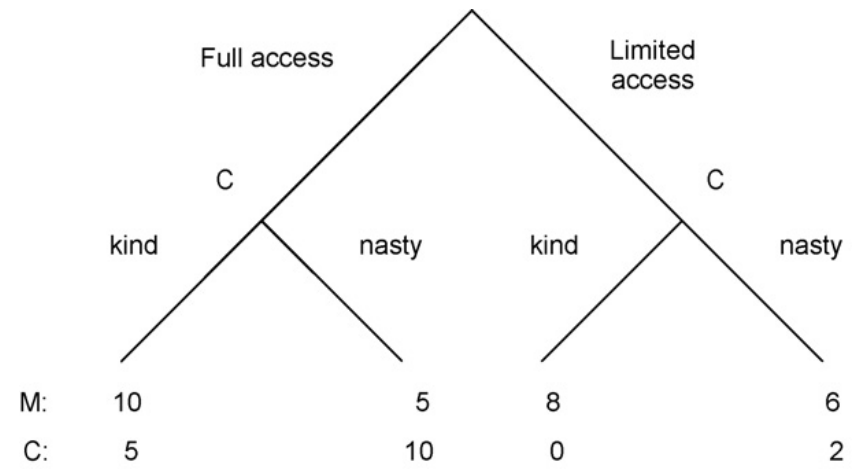

Fig. 3. The "Magnatune" game.

stores is $\$ 8$ and the kind voluntary payment under full access is $\$ 10$. The value of listening is $\$ 15$. When the customer is uncertain about the value due to the limited pre-purchase access the value is only $\$ 8$. The 'leakage' in a DRM environment is $\$ 2 .{ }^{12}$ This represents the part of customers that turns to P2P file sharing. Store revenues ( $\$ 8$ ) are reduced by this.

The subgame-perfect equilibrium of the game is (limited access (nasty, nasty)). M would not be willing to offer full access knowing that $C$ will prefer the higher payoff of playing nasty (paying the minimum only). Instead, M offers limited access and C plays nasty (using P2P copies if possible). This would mean labels operate with fixed prices exclusively and some piracy occurs.

However, this solution is not in line with the collected data. The observed pattern of behaviour corresponds more to an outcome of (full access, kind). Moving away from strictly selfish individuals and introducing social preferences helps in order to explain what we see in the data. Social preferences do not give up the assumption that individuals maximize their utility. They merely allow utility to reflect social concerns as well. Besides individuals' own payoffs it matters to them as well what the payoffs and intentions of other individuals are. A few theoretical approaches exist and they are surveyed in Fehr and Schmidt (2003) as well as Camerer (2003).

We focus on concerns for reciprocity to explain the observed behaviour of Magnatune customers. The provision of comprehensive pre-purchase access can be regarded as kind behaviour by customers as it allows them to make a more informed purchase choice. Hence, if customers have social preferences, they are willing to return this kind treatment. In contrast, selfish customers would free ride. The open contract design - customers are free to choose the payment from a given range - provides opportunities to reciprocate by making a high voluntary payment. Fairness and reciprocity can also be regarded as the enforcement device of this contract design.

We apply social preferences to the "Magnatune" game based on Dufwenberg and Kirchsteiger (2004). A sequential reciprocity equilibrium ${ }^{13}$ of (full access (kind, nasty)) results when (sufficient) players have a tendency to reciprocate. The known equilibrium of (limited access (nasty, nasty)) results when individuals are insufficiently motivated by reciprocity, e.g. are selfish.

\subsection{Sequential reciprocity theory}

This section outlines how the sequential reciprocity equilibrium of the game is determined based on the seminal work of Rabin (1993) and Dufwenberg and Kirchsteiger (2004). The utility function of socially minded individuals increases not only in their material payoffs but also in the psychological payoffs which depend on the individuals' kindness to others and their beliefs about the kindness of the other individual towards themselves. The resulting games are solved using the psychological games framework of Geanakoplos et al. (1989).

While the action set $a_{i}$ describes the choices of player $i$ (e.g. the access provided by M or the chosen payment of the customer), $b_{i j}$ defines the belief of $i$ about the choices of player $j$, whereas $\tilde{b}_{i j i}$ is $i$ 's belief about what $j$ believes are $i$ 's choices. This framework of beliefs allows us to express the kindness and beliefs about the kindness of individuals towards another individual. This is achieved by comparing an actual payoff $\Pi$ to the equitable or fair payoff of a player, $\Pi^{e}$.

The equitable payoff of an individual is the average of his best and worst outcome based on the choices of the other individual. ${ }^{14}$ For agent $j$ it is given by:

$$
\Pi_{j}^{e}\left(b_{i j}\right)=\frac{1}{2}\left(\max \left\{\Pi_{j}\left(a_{i}, b_{i j}\right)\right\}+\min \left\{\Pi_{j}\left(a_{i}, b_{i j}\right)\right\}\right)
$$

\footnotetext{
12 If piracy is ubiquitous and unstoppable, then the revenue under DRM is zero and M prefers "full access". A moderate amount of piracy and thus leakage is more reasonable.

13 See Dufwenberg and Kirchsteiger (2004) for their theory of sequential reciprocity to solve games with belief-dependant motivations.

14 The average is used here because it is straightforward. Using another intermediate value is also possible and it does not affect the qualitative results. See also Dufwenberg and Kirchsteiger (2004) footnote 7.
} 
It can be seen as a reference point for how kind $i$ is to $j$ as this kindness $\kappa_{i j}$ is expressed by relating the actual payoff $j$ is given by $i$ to the equitable payoff of $j$ :

$$
\kappa_{i j}\left(a_{i}, b_{i j}\right)=\Pi_{j}\left(a_{i}, b_{i j}\right)-\Pi_{j}^{e}\left(b_{i j}\right)
$$

Similarly $i$ 's belief about the kindness of $j$ to $i$ is:

$$
\tilde{\kappa}_{i j i}\left(b_{i j}, \tilde{b}_{i j i}\right)=\Pi_{i}\left(b_{i j}, \tilde{b}_{i j i}\right)-\Pi_{i}^{e}\left(\tilde{b}_{i j i}\right)
$$

Incorporating kindness and the beliefs about it gives the following utility function with a material payoff as the first term and the reciprocity payoff in the second term that is weighted by the sensitivity to reciprocity $\alpha$ ( $\alpha=0$ is the special case of pure self-interest).

$$
U_{i}=\Pi_{i}\left(a_{i}, b_{i j}\right)+\alpha_{i} \cdot \kappa_{i j}\left(a_{i}, b_{i j}\right) \cdot \tilde{\kappa}_{i j i}\left(b_{i j}, \tilde{b}_{i j i}\right)
$$

The condition to solve the game is that in equilibrium all beliefs and second order beliefs are correct. It is also important to mention that beliefs of players are updated over the course of the game. Once an action of a player has taken place, beliefs involving randomisation about this action are replaced by pure choice beliefs as the individuals apply Bayesian updating.

A positive reciprocity equilibrium exists. The customer will make a voluntary payment, if her sensitivity to reciprocity is large enough: $\alpha_{C}>\bar{\alpha}_{C}$. The possibility of $\alpha_{C}<\underline{\alpha}_{C}$ corresponds to the negative reciprocity equilibrium.

After establishing conditions for $C$ to make a voluntary payment once $M$ has allowed full access, it has to be analysed whether $M$ will ever provide full access in the first place. He knows that the customer will always pay the minimum when $\alpha_{C}<\underline{\alpha}_{C}$ and therefore he will never allow full access in that case. This constitutes the sequential reciprocity equilibrium of (limited access (nasty, nasty)).

$\mathrm{M}$ also knows that $\mathrm{C}$ will act reciprocally once her sensitivity to reciprocity $\alpha_{C}$ is large enough. That means he assumes $\mathrm{C}$ will reward the choice of full access with a voluntary payment and will possibly reply to limited access with piracy. It can be shown that the condition for $\mathrm{M}$ to make the full access decision is always fulfilled and the sequential reciprocity equilibrium of (full access (kind, nasty)) results.

Applying sequential reciprocity theory we can explain when customers make a voluntary payment. Social preferences are necessary which are incorporated into the utility function with a reciprocity payoff. Once reciprocity gains (from returning kind behaviour) outweigh the material loss of making the higher payment ( $p_{v}$ instead of $p_{\min }$ ), customers will prefer to make a voluntary payment. However, they have to be sufficiently motivated by reciprocity, e.g. $\alpha$ - their sensitivity to reciprocity - has to be large enough. Moreover, $\mathrm{M}$ has to believe that the aggregated $\alpha$ of the customer pool is large enough in order to provide full access in the first place.

\subsection{Further discussion}

The strategic setting of the "Magnatune" game has been presented in this section. An equilibrium solution based on social preferences and concerns for reciprocity has been developed which explains the voluntary payments in the analysed data.

The focus on reciprocity appears to be a good fit for the given context of an online music store like Magnatune. However, reciprocity is just one possible theoretical approach and other motivations - or a combination of them - may also explain the voluntary payments. Two other plausible motives (the "warm glow" from contributing to a good cause and guilt, the burden of paying less than one should) will also be outlined.

Trying to appeal to the morality of customers seems plausible in the highly charged field of online music. In fact, Magnatune also specifically addresses this on its web site. It promises "Internet music without the guilt".

The emotion of guilt could therefore be induced by the fact that while albums can be had for only $\$ 5$, the site recommends to pay \$8. Customers are given the opportunity to pay something for the music in contrast to the downloading from P2P networks where no payments are possible. A latent guilty feeling from downloading might remain, whereas the Magnatune customers are provided with a mechanism to alleviate that-specifically reminded by the site.

Modeling emotions like guilt in detail will require an extended psychological analysis. However, a basic approach to take emotions into account would be a simple cost-benefit model (Elster, 1998). Guilt could be seen as a psychic cost that is integrated into the utility function along with the material payoffs. A trade-off between the moral emotions and material self-interest is created comparable to a reciprocity payoff. When the psychic cost of guilt - e.g. the moral burden of paying less than one should - outweighs the material gain, the customer would decide to pay more to alleviate the guilt induced.

The customer's choice depends on how sensitive to guilt she is. This can be expressed by the individual's sensitivity to experience guilt $\gamma$. Paying only the minimum causes a psychic cost of guilt, which however may not affect the customer's utility if she is "immune" against it. Customers with insignificant levels of $\gamma$ will likely not respond to the induced guilt. Instead, customers with a high sensitivity to guilt may chose to make a voluntary payment as this alleviates their guilt and maximizes their utility. The psychological games framework introduced in Section 5.4 can also be applied in the context of guilt, see Ruffle (1999) or Dufwenberg (2002).

The voluntary payments of Magnatune customers could also be seen as their private contributions to a public good. Customers might like the basic idea of the service (quality music for a reasonably low price, equal share between artist and label, no DRM and comprehensive pre-purchase access) and might want to support Magnatune and the respective artist. 
Thus, they contribute with a voluntary payment in order to support the label and as well the artist being active in the future which is of benefit for them.

While neoclassical theory predicts free riding and less than efficient payments of individuals in such a public good context, ${ }^{15}$ in practice contributions are higher than what purely selfish players would chose in these settings. Andreoni (1990) suggests that individuals not only derive the standard indirect benefit from their contributions (e.g. future consumption of the good), but also a direct benefit, a so-called "warm glow" from contributing to a good cause. Being proud of this act of kindness may be one inherent reason for the warm glow mechanism.

The direct benefit of a payment (or contribution) is weighted by the individual's sensitivity to the warm glow mechanism $\beta$. Whether a customer then decides to contribute essentially depends on her sensitivity to experience warm glow. If a customer is not open at all to such emotions (e.g. if $\beta=0$ ), in deed no contribution beyond the minimum is rational. On the other hand, when a significant sensitivity to warm glow is present, a contribution, e.g. a voluntary payment, results.

Reciprocity, warm glow and guilt all explain voluntary payments in the open contracts design when a specific customer's sensitivity (to reciprocity $(\alpha)$, to the warm glow mechanism $(\beta)$, to experience guilt $(\gamma)$ ) is large enough. Therefore, voluntary payments of one customer should not be randomly distributed, but rather be somewhat sticky, depending mostly on the sensitivity parameter of the customer. This is in line with the observed data as we were able to distinguish between different types of payment behaviour among frequent customers. If the voluntary payments are caused by a customer-specific underlying motivation, then transactions across customers should vary, while transactions from frequent customers should show consistent type-dependent patterns. Hence, knowing that the size of payments is quite specific to individuals can be seen as further evidence that the payments are motivated by social preferences instead of some unobservable factor or just due to complete randomness.

\section{Conclusions}

The observed pattern of behaviour - consumers do pay voluntarily - can be explained with a sufficiently high level of social preferences. The analysis of the strategic interaction between label/artists and customers shows that making a voluntary payment constitutes a sequential reciprocity equilibrium. The link to the theory focuses on reciprocity as the source of social preferences, because of the comprehensive and free pre-purchase access of Magnatune that allows customers to make an informed buying decision. This aspect appears to be of significant relevance in the context of information goods markets. Ample opportunities to sample yet unknown songs could well be regarded as kind behaviour by sufficiently socially minded customers thus triggering a kind reaction. A voluntary payment is made, while self-interested customers only pay the minimum.

However, with the existing data set it is not possible to confirm that reciprocity is the main motivation for the observed voluntary payments. Other possible underlying motives for social preferences ("warm glow" (feeling good from contributing to a worthy cause) and guilt (the burden of paying less than one should)) are suggested that appear realistic in the analysed context of an online music store. It may well be that all of them are significant and more specific data is necessary to distinguish between the identified sources. Such an analysis remains for further research. Nevertheless, all three underlying motives - reciprocity, warm glow and guilt - explain the payment behaviour with socially minded customers who maximize their utility. All three theories are based on a sensitivity parameter (to reciprocity, warm glow or to experience guilt) that is specific to individuals. This can be verified in the payment patterns of frequent customers where four distinct groups can be identified: customers who essentially always pay the minimum, the default, customers who pay significantly more than the average and the ones with a negative time trend.

Compared to a conventional online music store that charges a fixed price of - for instance - \$8 an album (and offers only limited sampling possibilities if at all) Magnatune makes more visitors acquainted with its songs and thus turns more visitors of the site into customers; and on average they still pay more than the recommended price of $\$ 8$. Of course, we could only speculate about the revenue, if a label charged a fixed price of more than $\$ 8$. Our analysis cannot provide such a counterfactual, but a related study (Gneezy, 2009) finds that a loss from a name-your-own-price that is on average lower than the fixed price is offset by the higher volume. Finally, Magnatune is now at a break-even point according to the owner.

Nevertheless, despite the success of Magnatune's voluntary payments scheme it is important to stress that several conditions seem necessary to make the scheme work. Magnatune artists are rather unknown and the results cannot be easily applied to the mass market. The tendency of customers to make a voluntary payment should be seriously affected if the artist is a millionaire already. Hence, an open contracts design should be regarded as a promising alternative to strictly DRM-based online music stores. In a possible life-cycle of artists the market of Magnatune takes its position in an early stage where artists are not (yet) well-known. ${ }^{16}$ In this phase the experience good aspect of pre-purchase access is relatively more important in order to get exposure than for established artists. However, it may not necessarily be wealth and popularity of artists that limits the applicability of the scheme as Radiohead - a famous yet alternative rock band - offered their 7th album online for

\footnotetext{
15 When individuals only care about their consumption of private and public goods the resulting Nash equilibrium for the contribution level to the public good is less than what is socially optimal.

16 See also Regner et al. (2009).
} 
free and encouraged voluntary payments; apparently very successfully. ${ }^{17}$ Other conditions for a fruitful environment that encourages voluntary payments appear to be a fair sharing of revenue with the artists, a price range that takes the market price for CDs and downloads into account and a high degree of customer appreciation.

\section{References}

Amemiya, T., 1984. Tobit models: a survey. Journal of Econometrics 24, 3-61.

Andreoni, J., 1990. Impure altruism and donations to public goods: a theory of warm glow giving. Economic Journal 100 (401), $464-477$.

Camerer, C., 2003. Behavioral Game Theory: Experiments in Strategic Interaction. Princeton University Press, Princeton.

Cragg, J.G., 1971. Some statistical models for limited dependent variables with application to demand for durable goods. Econometrica 39, 829-844.

Dufwenberg, M., 2002. Marital investments, time consistency and emotions. Journal of Economic Behavior and Organization 48, 57-69.

Dufwenberg, M., Kirchsteiger, G., 2004. A theory of sequential reciprocity. Games and Economic Behavior 47, 268-298.

Elster, J., 1998. Emotions and economic theory. Journal of Economic Literature 36, 47-74.

Fehr, E., Gächter, S., Kirchsteiger, G., 1997. Reciprocity as a contract enforcement device: experimental evidence. Econometrica 65, 833-860.

Fehr, E., Schmidt, K., 2003. The economics of fairness, reciprocity and altruism-experimental evidence and new theories. In: Kolm, S., Ythier, J. (Eds.), Handbook of Reciprocity, Gift-Giving and Altruism. Elsevier, pp. 616-690, 2006.

Frey, B., Meier, S., 2004. Social comparisons and pro-social behavior: testing “conditional cooperation” in a field experiment. American Economic Review $94 / 5,1717-1722$.

Geanakoplos, J., Pearce, D., Stacchetti, E., 1989. Psychological games and sequential rationality. Games and Economic Behavior 1, 60-79.

Gneezy, U., 2009. On fairness in markets. Mimeo.

Indicare, 2005. Digital Music Usage and DRM: Results from an European Consumer Survey. In: Dufft, N. (Ed.), Berlin, 24 May 2005, available online at: http://www.indicare.org/tiki-download_file.php?fileId=110.

List, J., Lucking-Reiley, D., 2002. The effects of seed money and refunds on charitable giving: experimental evidence from a university capital campaign. Journal of Political Economy 110, 215-233.

Rabin, M., 1993. Incorporating fairness into game-theory and economics. American Economic Review 83, $1281-1302$.

Regner, T., Barria, J.A., Pitt, J., Neville, B., 2009. An artist life-cycle model for digital media content. Mimeo.

Ruffle, B.J., 1999. Gift giving with emotions. Journal of Economic Behavior and Organization 39, 399-420.

World Bank, 2004. Statistics.

17 See http://en.wikipedia.org/wiki/Radiohead. 